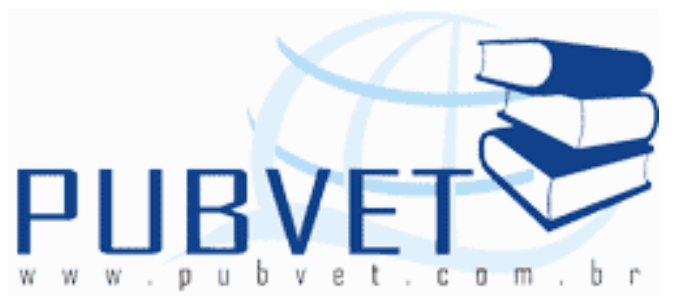

PUBVET, Publicações em Medicina Veterinária e Zootecnia.

\title{
Análise da qualidade de vida do pequeno produtor de leite de um laticínio em Douradoquara - MG
}

\section{Franco da Silva e Souza ${ }^{1}$ e Cláudio Costa $^{2}$}

${ }^{1}$ Graduando em Administração - FUCAMP - 2011.

${ }^{1}$ Professor Orientador - FUCAMP - 2011.

\section{Resumo}

A produção brasileira de leite se destaca com índices de produção elevados, porém um a cada três estabelecimentos rurais se caracteriza como agricultura familiar. O objetivo desta pesquisa foi avaliar a qualidade de vida do pequeno produtor de leite de um laticínio em Douradoquara - MG. Foi desenvolvido um questionário e aplicado aos setenta e seis produtores com produção diária de leite abaixo de 150 litros, e que fornecem leite ao laticínio estudado. A pesquisa constatou que a maioria deles já está na atividade há mais de vinte anos e residem no meio rural, além de possuírem veículos próprios e acesso a tecnologias atuais como celulares e computadores. Conclui-se que mesmo com todas as dificuldades enfrentadas os produtores estão comprometidos com a atividade. Avaliando-se a qualidade de vida em que estão inseridos constata-se que eles se enquadram num padrão razoável de conforto e têm acesso aos mesmos benefícios que os moradores urbanos.

Palavras-chave: Produção; Qualidade; Leite. 


\section{Abstract}

The Brazilian milk production highlight with levels of high production, but one each three farms appear as family farming. The objective of this search was measure the life quality of the small milk producer of a milk industry in Douradoquara - MG (Brazil). It was developed a questionnaire and applied to the seventh six producers with daily milk production less than 150 liters, and they supply the studied milk industry. The search show the most of them are producing for more than twenty years and they live in the country, beyond they have own car and access to current technologies when mobile and computers. It's concluded, same as all the faced difficulties the producers are committed with the activity. Evaluating the life quality that the producers live notes they fit in a reasonable standard of comfort and they have access to same benefits than the city residents.

Keywords: Production; Quality; Milk.

\section{Introdução}

O agronegócio brasileiro gera renda e emprego através da produção de cem milhões de toneladas de grãos colhidos em 2010, correspondendo a $7,8 \%$ do produto interno bruto neste ano, além de impulsionar a economia através da exportação da produção. O agronegócio relacionado a sustentabilidade revela em seu paradigma uma produção cada vez maior além de ter investimentos significativos em tecnologia, integrada a globalização proporcionando produção em escala industrial (BARROS; LIMA; FERNANDES, 2010).

O agronegócio pode ser entendido como atividades de cadeias produtivas agropecuárias, que envolvem a comercialização, industrialização e produção de matéria-prima para que haja então um encadeamento de operações observadas em suas três fases conhecidas como antes, dentro e depois da porteira (CORONEL; MACHADO; DUTRA, 2007). O agronegócio passa a ser conhecido também como agribusiness, e esse reconhecimento 
não veio por acaso, já que exerce uma verdadeira articulação que engloba agroindústria, mercado, distribuidores e consumidor (NEVES, 2007).

As explorações leiteiras tradicionais no Brasil,foram iniciadas com a chegada dos primeiros colonos portugueses, já no mundo a história registra a produção de leite desde a pré-história. Porém somente após a Segunda Guerra Mundial se processaram mudanças drásticas na produção leiteira modificando-se assim o caráter de produção familiar e rudimentar e transformando essa atividade numa indústria sofisticada em muitas partes do mundo (SANTOS; VILELA, 2000).

De acordo com Souza e Waquil (2008), um em cada três estabelecimentos produtores de leite é classificado em agricultura familiar, e produzem alguma quantidade de leite. A produção de leite se expande devido ao fato de não haver praticamente nenhuma barreira à entrada, além do leite ser um produto para consumo interno, permitindo a obtenção de renda mensal. Ainda permite o uso de terras não-nobres e utilização de forma intensiva da mão-de-obra familiar. Porém, as transformações na cadeia produtiva e as legislações têm elevado a pressão para a especialização dos produtores, colocando em risco a permanência de muitos na atividade.

A produção em âmbito industrial, para Neves (2007), segue um posicionamento que exige uma maior produtividade a cada instante. Assim, a fase depois da porteira estabelece as relações comerciais voltadas para atender as expectativas dos clientes, procurando através da acessibilidade ter um produto no qual condiciona marca e valor (MESQUITA, 2007). As operações de produção, distribuição de suprimentos agrícolas e armazenamento, conforme Peres (2001) presenciam uma mentalidade fundamental para o agronegócio. Isso quer dizer que sempre busca aumentar a produtividade. Porém quando se fala nessa mentalidade, deve estar atento ao desempenho no campo diante da produtividade para que não se tenham prejuízos ao utilizar procedimentos inadequados. Assim, o 
objetivo deste estudo foi analisar a qualidade de vida do pequeno produtor de leite de um laticínio em Douradoquara - MG no ano de 2011.

\section{Referencial teórico}

A produção nacional de leite acompanhou o processo de urbanização, visto que as bacias leiteiras se formaram com o objetivo de atender 0 mercado de consumidores urbanos, e atualmente tornou-se raro encontrar um município que não tenha pelo menos uma vaca leiteira demonstrando a importância que a atividade adquiriu, tanto no desempenho econômico como na geração de empregos. A produção apresenta um constante crescimento visto que o volume de leite em 2009 foi de aproximadamente 29,11 bilhões de litros, enquanto que em 2010 a produção se aproximou de 30,36 bilhões de litros. O Brasil possui o segundo maior rebanho leiteiro mundial, com aproximadamente 21.198 mil animais, ficando atrás apenas da Índia (PACHECO, 2011).

Conforme Carvalho, Carneiro e Stock apud Pacheco (2011), o setor de lácteos é voltado para o mercado doméstico, e recentemente se inseriu no mercado internacional, visto que historicamente o país é um importador desses produtos, fato que pode ser explicado à suficiência do mercado interno para absorção da produção nacional, tornando desnecessário o esforço para exportação.

A produção leiteira no Brasil, de acordo com Santos (2008), distribuise de maneira heterogênea em relação ao processo produtivo, visto que os produtores especializados investem em tecnologia e diferenciam seus produtos para receberem pelo volume produzido e pela qualidade alcançada, se concentrando em bacias leiteiras tradicionais nas regiões Sul, Sudeste e Centro-Oeste. A atividade leiteira se modernizou nas últimas décadas, porém houve redução do número de produtores e principalmente da quantidade de vacas ordenhadas.

Assim, os produtores que permaneceram na atividade se conscientizaram em relação à necessidade de implantação de melhorias no 
processo produtivo. A busca pela qualidade mudou o nível de tecnologia nas unidades de produção, proporcionando o uso de ordenha mecânica e tanques de resfriamento.

Borges et al. (2011) afirmam que os sistemas de produção de leite in natura são bastante heterogêneos, sendo compostos por produtores que trabalham com tecnologias modernas e outros com processos rudimentares, sendo possível classificar dois tipos de produtores, ou seja, os especializados e os não especializados. O produtor especializado trabalha com uma estrutura que the possibilite a geração de excedentes, enquanto os não especializados trabalham com tecnologia rudimentar. Assim, para os próximos dez anos, no curto prazo, deverá continuar havendo reduções importantes do número de produtores, principalmente dos que operam com custos elevados, pequenas escalas e mão-de-obra assalariada.

Outro aspecto a ser observado é o processo de modernização no setor lácteo brasileiro, benéfico na medida em que melhora a qualidade do produto, reduz o risco de contaminação nos produtos e, pode contribuir para uma futura orientação externa do setor, o que ressalta a importância da profissionalização dos produtores não-especializados, visto que se estes não conseguirem se adaptar aos padrões de qualidade sanitária serão exclusos do mercado (BARROS et al., 2011).

De acordo com Gomes (2007), a produção de leite no Brasil foi considerada uma atividade atrasada, com índices de produtividade baixos devido aos sistemas de produção pouco tecnificados resultando numa produtividade que girava em média de três litros/vaca/dia. Com o tempo esse quadro mudou $e$, nos últimos anos, a produção aumentou consideravelmente tanto em litros/vaca, litros/hectare e litros/dia/hectare. Em Minas Gerais, produtores com produção de até 50 litros/dia representavam $44 \%$ do total e produziam apenas $8 \%$ da produção, enquanto que os produtores de mais de 500 litros/dia eram $7 \%$ do total e produziam $45 \%$ da produção, o que demonstra que os grandes produtores são responsáveis por grande parte do abastecimento leiteiro, porém, os 
pequenos produtores vêm a cada dia melhorando seus processos para poderem permanecer no segmento leiteiro.

Conforme Carvalho, Souza e Brasil (2010) o agronegócio brasileiro tem grande potencial de crescimento, visto que o mercado interno é expressivo, e o mercado internacional apresenta acentuado crescimento no consumo devido a influência de países mais populosos que têm dificuldades de atender às demandas por esgotamento de suas áreas agricultáveis. Assim, as dificuldades de ressuprimento de estoques mundiais, o acentuado aumento do consumo devido ao crescimento da população e o processo de urbanização no mundo, cria condições favoráveis ao Brasil de produzir para suprir o mercado nacional e internacional. Porém, observa-se que as condições de produção dos agricultores, visto que a atividade possui poucos grandes produtores e muitos pequenos produtores atuando no segmento.

De acordo com a Associação Brasileira de Qualidade de Vida (ABQV) apud Carvalho, Souza e Brasil (2010), a expressão "qualidade de vida" atribui-se ao presidente dos Estados Unidos, Lyndon Johnson, declarou em 1964 que os objetivos não podiam ser mensurados através do balanço dos bancos e sim através da qualidade de vida que eles proporcionavam às pessoas.

Antes disso, os conceitos de qualidade de vida já despertavam interesses de muitos estudiosos, sendo identificadas duas tendências, uma ligada ao conceito genérico e outra ligada à saúde. A primeira apresenta uma acepção ampla, influenciada por estudos sociológicos, sem fazer referência a disfunções ou agravos, enquanto a relacionada à saúde engloba dimensões específicas da saúde. Assim, a Organização Mundial da Saúde (OMS) conceitua o termo como a percepção que o indivíduo tem sobre sua posição no contexto da cultura e do sistema de valores nos quais vive, e em relação aos objetivos, expectativas, padrões e preocupações.

Kageyama e Rehder apud Balsadi e Gomes (2007) foram os pioneiros em pesquisas para mensuração do bem estar rural em diferentes estados do Brasil na década de 1980, e propuseram o Índice de Bem Estar Social Rural 
(IBES), construído a partir de quatro dimensões, por meio de doze indicadores e quatro índices parciais, sendo considerada a educação, a renda, as condições de trabalho e condições do domicílio.

Para Herculano (2000) qualidade de vida pode ser avaliada como a capacitação para alcançar funcionalidades, tais como se nutrir adequadamente, ter saúde, abrigo, segurança, auto-respeito e integração social e essa capacitação dependerá de um conjunto de fatores de acordo com cada indivíduo, visto que cada um possui características de personalidade e de arranjos sociais e assim, cada pessoa enxerga a qualidade de vida de acordo com suas condições e visões e o que é bom para um grupo pode não ser adequado para outro.

Uma maneira apontada para o aumento de renda e conseqüente melhoria na qualidade de vida da população rural é enfatizar a pluriatividade, ou seja, desenvolvimento de mais de uma atividade na propriedade, servindo esse como um elo de ligação entre as políticas agrícolas de crédito, assistência técnica, sanitárias e de abastecimento e as políticas de desenvolvimento rural, tais como o beneficiamento e a transformação da produção, agregando valor via agroindustrialização (BALSADI; GOMES, 2007).

\section{Metodologia}

O município de Douradoquara, conforme censo realizado pelo Instituto Brasileiro de Geografia e Estatística (IBGE) em 2010, conta com uma população de 1.841 habitantes, numa área territorial de $312.878 \mathrm{Km}^{2}$, sendo que existem 247 estabelecimentos agropecuários em que 185 produziram leite em 2006 com uma produção de 6.939 mil litros de leite no ano.

A atividade leiteira no município envolve a geração de renda e emprego. Existe na cidade apenas um laticínio, o qual absorve parte da produção de leite do município, acredita-se que $60 \%$ da mão de obra esteja envolvida direta e indiretamente com a produção e o beneficiamento de 
leite. No âmbito econômico trata-se da segunda fonte geradora de ICMS da cidade, ficando atrás apenas da CEMIG, sendo a maior parte do comércio local movimentado diretamente com a atividade leiteira.

O laticínio observado possui sua matriz em São Paulo - SP e opera com mais três unidades industriais em grandes bacias leiteiras do Brasil, sendo produtora de queijos e outros derivados do leite, e a comercialização dos laticínios abrange todo o território nacional. São produzidos mais de 30 tipos de queijos nos quais cada unidade tem suas especificações. Sua área de atuação é específica na produção de queijos Gorgonzola e hoje já consegue arrecadar 33.000 litros por dia para o processo produtivo.

A pesquisa foi realizada através de levantamento teórico sobre o agronegócio leiteiro a partir de consultas a artigos científicos que tratam do assunto. Foi elaborado um questionário baseado em Brito (2006) e aplicado aos pequenos produtores de leite residentes no município e região de Douradoquara - MG.

O questionário foi composto por 16 questões de múltipla escolha nas quais as quatro primeiras questões avaliaram o perfil sócio-econômico dos produtores. As próximas três analisaram as condições de trabalho, enquanto que as três próximas avaliaram a posse de bens duráveis e não duráveis. As cinco últimas abordaram o comprometimento dos produtores com a atividade leiteira. O método utilizado para a coleta das respostas foi entrevista, em que o aplicador leu as questões e os produtores de leite escolheram a opção que mais se enquadravam a realidade vivenciada. Essa etapa de aplicação de questionários foi realizada no mês de outubro de 2011.

A entrevista foi realizada em várias propriedades rurais para aplicar as questões com base no banco de dados fornecido pelo laticínio. Depois de aplicados os dados foram tabulados e analisados para se conhecer a realidade da qualidade de vida desses produtores. Para esse estudo foram considerados os produtores que produzem até 150 litros e fornecem sua produção para o laticínio, o que resultou em uma amostra de 76 produtores. 
SOUZA, F.S. e COSTA, C. Análise da qualidade de vida do pequeno produtor de leite de um laticínio em Douradoquara - MG. PUBVET, Londrina, V. 7, N. 23, Ed. 246, Art. 1623, Dezembro, 2013.

\section{Resultados e discussão}

A Tabela 1 avaliou o perfil socioeconômico dos pequenos produtores. A faixa etária encontra-se entre 26 e mais de 66 anos, e que acima de 46 anos encontram-se $73,7 \%$ dos produtores de leite que fornecem sua produção ao laticínio e nenhum com menos de 25 anos. Ao questionar sobre o tempo em que exercem a atividade, $57,9 \%$ declararam estarem no segmento de produção de leite há mais de 20 anos, ou seja, já têm experiência no ramo e já passaram por várias dificuldades. Avaliando-se os que produzem há mais de 15 anos a amostra chega a mais de 63\%. Em relação à escolaridade desses produtores constatou-se que mais da metade deles possui apenas nível primário completo contra apenas 7,9\% com ensino superior completo. Três quartos da amostra residem no meio rural, ou seja, fixaram moradia na propriedade em que produzem o leite. Já os $25 \%$ de produtores que possuem moradia na cidade declararam que preferem morar no meio urbano, em $33,3 \%$, pelo conforto e outros $27,8 \%$ por terem filhos em idade escolar.

A Tabela 2 avaliou as condições de trabalho dos produtores. Ao pesquisar sobre a infraestrutura básica de suas moradias constatou-se que a grande maioria possui condições básicas, como banheiro, água encanada e eletricidade. Em $79 \%$ os produtores são os proprietários da parcela de terra em que criam o gado para a produção de leite e apenas $11,8 \%$ as terras utilizadas na atividade são de propriedade de terceiros e, nesse caso o produtor de leite aluga ou arrenda a propriedade para desenvolver o ofício. Em 9,2\% dos produtores as terras pertencem a outro membro do agregado familiar, como pais ou outros parentes próximos.

Ao serem questionados sobre a forma de aquisição da propriedade, no caso dos $79 \%$ que são donos da fazenda, $75 \%$ declararam que compraram as terras e em $25 \%$ herdaram. Houve casos em que houve mais de uma maneira de aquisição, sendo que nesses casos a aquisição foi em parte herdada e em parte comprada para a expansão do negócio. Em 5,3\% 
SOUZA, F.S. e COSTA, C. Análise da qualidade de vida do pequeno produtor de leite de um laticínio em Douradoquara - MG. PUBVET, Londrina, V. 7, N. 23, Ed. 246, Art. 1623, Dezembro, 2013.

a aquisição foi por doação, considerando-se projetos desenvolvidos pelo governo.

Tabela 1: Perfil socioeconômico do pequeno produtor de leite de um lacticínio no município de Douradoquara - MG.

$$
\text { No }
$$

Questões produtores $\%$

\section{Qual a idade:}

a 18 a 25 anos

0

b 26 a 35 anos

8

c 36 a 45 anos

d 46 a 55 anos

25

e 56 a 65 anos

14

$0,0 \%$

$f$ Mais de 66 anos

$10,5 \%$

$15,8 \%$

$22,4 \%$

$32,9 \%$

$18,4 \%$

\section{Há quanto tempo está na atividade?}

\begin{abstract}
a Menos de 5 anos
bEntre 5 e 10 anos

c Entre 10 e 15 anos

dEntre 15 e 20 anos

e Mais de 20 anos
\end{abstract}

$\begin{array}{cc}8 & 10,5 \% \\ 14 & 18,4 \% \\ 6 & 7,9 \% \\ 4 & 5,3 \% \\ 44 & 57,9 \%\end{array}$

\section{Qual a alfabetização do respondente?}

$\begin{array}{lcc}\text { a Não sabe ler nem escrever } & 1 & 1,3 \% \\ \text { b Sabe ler/escrever sem grau de ensino } & 14 & 18,4 \% \\ \text { c Ensino primário completo } & 40 & 52,6 \% \\ \text { dEnsino secundário } & 10 & 13,2 \% \\ \text { e Ensino médio/profissional } & 5 & 6,6 \% \\ \text { f Ensino superior incompleto } & 0 & 0,0 \% \\ \text { gEnsino superior completo } & 6 & 7,9 \%\end{array}$

\section{Onde reside?}

$\begin{array}{lll}\text { a Zona rural } & 57 & 75,0 \% \\ \text { bZona urbana } & 19 & 25,0 \%\end{array}$

\section{Se morar na cidade, qual o motivo?}

\begin{tabular}{lll} 
a Conforto & 6 & $33,3 \%$ \\
b Filhos na escola & 5 & $27,8 \%$ \\
c Facilidade para negociação & 4 & $22,2 \%$ \\
d Melhor acesso a serviços e produtos & 3 & $16,7 \%$ \\
\hline
\end{tabular}


A mão de obra utilizada nas propriedades é em grande parte permanente, alcançando $86,8 \%$ dos produtores. Os demais produtores utilizam a mão de obra esporádica, utilizando empregados diaristas em períodos necessários. Zoccal et al (2004), em uma pesquisa parecida realizada na Zona da Mata em Minas Gerais constatou que na sua amostragem, $36 \%$ dos produtores contratam mão-de-obra permanente contra $72 \%$ que utilizam a mão de obra temporária, utilizada principalmente para a limpeza dos pastos, plantio ou colheita de outras culturas desenvolvidas na propriedade, produção de silagem e construções de cercas, apresentando assim, na região analisada por ele, resultados contrários aos dessa pesquisa.

Tabela 2: Levantamento das condições de trabalho do pequeno produtor de leite de um lacticínio no município de Douradoquara - MG.

Questões

No

Infraestruturas disponíveis na habitação?

a Água encanada

b Eletricidade

c Fossa sanitária

dBanheiro

e Nenhuma

produtores

$\%$

72

75

61

70

0
$94,7 \%$

$98,7 \%$

$80,3 \%$

$92,1 \%$

$0,0 \%$

\section{É proprietário da parcela de terra onde produz?}

\begin{tabular}{lcc} 
a Sim & 60 & $79,0 \%$ \\
b Não & 9 & $11,8 \%$ \\
c Outro membro do agregado familiar & 7 & $9,2 \%$ \\
\hline Se for proprietário, como adquiriu? & & \\
a Herança & 19 & $25,0 \%$ \\
b Compra & 57 & $75,0 \%$ \\
c Doação & 4 & $5,3 \%$
\end{tabular}

\section{Mão de obra utilizada na propriedade:}

a Diarista 
SOUZA, F.S. e COSTA, C. Análise da qualidade de vida do pequeno produtor de leite de um laticínio em Douradoquara - MG. PUBVET, Londrina, V. 7, N. 23, Ed. 246, Art. 1623, Dezembro, 2013.

A Tabela 3 buscou avaliar a aquisição de bens duráveis pelos pequenos produtores e constatou-se que $82,9 \%$ deles possuem veículo próprio, e desses $57,1 \%$ possuem veículo com menos de onze anos de uso. Dentre todos os produtores que possuem veículo próprio, 9,5\% declararam terem adquirido o automóvel esse ano.

Tabela 3: Levantamento dos bens duráveis do pequeno produtor de leite de um lacticínio no município de Douradoquara - MG.

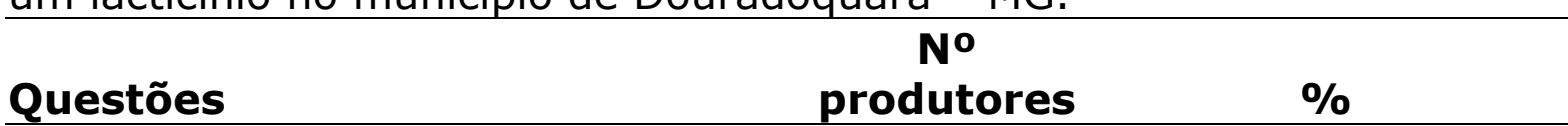

\section{Possui veículo próprio?}

\begin{tabular}{lcc} 
a Sim & 63 & $82,9 \%$ \\
b Não & 13 & $17,1 \%$ \\
\hline Qual o ano de fabricação? & 7 & \\
a $<1990$ & 7 & $11,1 \%$ \\
b 1990 a 1995 & 13 & $11,1 \%$ \\
c 1995 a 2000 & 9 & $20,7 \%$ \\
d 2000 a 2005 & 21 & $14,3 \%$ \\
e 2005 a 2010 & 6 & $33,3 \%$ \\
f $>2010$ & & $9,5 \%$
\end{tabular}

\section{Quais eletrodomésticos/eletrônicos possui?}

$\begin{array}{lcc}\text { a Liquidificador } & 71 & 93,4 \% \\ \text { bBatedeira } & 49 & 64,5 \% \\ \text { c Microondas } & 21 & 27,6 \% \\ \text { d Geladeira } & 70 & 92,1 \% \\ \text { eTelevisão } & 74 & 97,4 \% \\ \text { f Computador } & 21 & 27,6 \% \\ \text { gDvd/video-cassete } & 40 & 52,6 \% \\ \text { h Aparelho de som } & 58 & 76,3 \% \\ \text { i Notebook } & 7 & 9,2 \% \\ \text { j Celular } & 72 & 94,7 \% \\ \text { kMáquina de lavar roupas } & 61 & 80,3 \%\end{array}$

\section{Quais os tipos de equipamentos usados na atividade?}

\begin{tabular}{lcc} 
a Trator & 30 & $39,5 \%$ \\
b Ordenhadeira & 28 & $36,8 \%$ \\
c Tração animal (Carroça) & 63 & $82,9 \%$ \\
d Botujão criogênico de sêmen & 3 & $3,9 \%$ \\
e Nenhum & 5 & $6,6 \%$ \\
\hline
\end{tabular}


Em relação aos eletrodomésticos e eletrônicos a que esses produtores têm acesso, a maior ocorrência foi a televisão com 97,4\%. O aparelho celular teve $94,7 \%$ de ocorrências, deixando claro que a atividade rural, diferente do que ocorria antes da popularização da telefonia móvel, não é isolada ao campo e sim que mantêm comunicação com o resto do mundo, e ainda acompanha as inovações tecnológicas.

O produtor rural, antigamente, se precisasse de um produto ou serviço urbano necessitava se deslocar até o meio urbano para se comunicar. Atualmente esse fato não é mais necessário, pois mesmo em localidades com sinal de transmissão ruim há a possibilidade de instalações de antenas para que o ruralista possa se comunicar e ter acesso aos serviços distantes.

Com a expansão da rede elétrica ao meio rural, outro fato comprovado com a pesquisa é que os produtores de leite possuem acesso a vários eletrônicos, como batedeira, liquidificador, computadores, microondas e outros, levando para o campo uma forma de conforto que antes era destinado às cidades. A ocorrência de posse de geladeira alcançou 97,4\%, eletrodoméstico esse indispensável a conservação de alimentos. Balsadi e Gomes (2007), através de seus estudos, apontam que na região sudeste houve progresso dos ruralistas no acesso aos serviços, crescimento das participações das famílias em telefonia, obtenção de TV em cores e geladeira, porém, as condições de vida das famílias rurais ainda permanecem distantes em relação as famílias urbanas.

Ao serem questionados sobre os equipamentos que esses produtores possuem para o desenvolvimento da atividade leiteira, 82,9\% declararam que utilizam carroças com tração animal para o auxilio na produção, enquanto que $39,5 \%$ possuem trator. Em $36,8 \%$ os produtores utilizam a ordenhadeira para ordenhar as vacas, o que diminui os custos com mão de obra, além de aumentar a qualidade do leite produzido. Já, 6,6\% declararam não possuir nenhum equipamento para auxiliar na produção, desenvolvendo assim a atividade de maneira rústica. 
Um fato que deve ser considerado é que apenas 3,9\% dos produtores declararam possui o botijão criogênico de sêmen, equipamento utilizado para a fertilização artificial e melhoramento da qualidade do gado leiteiro para conseqüente aumento da produção diária.

Conforme Ferreira, Lopes e Ferreira (2001), é grande o potencial para aumento da produção leiteira em Minas Gerais, principalmente a pasto, já que o território mineiro situa-se em zona tropical, com produção de forragem o ano todo, visto que a alimentação é o que mais aumenta o custo de produção, e o pasto é o mais barato de todos os alimentos para se produzir e utilizar. A utilização da inseminação para melhoramento do gado e o aumento da produção, associados a expansão das pastagens geraria muitos retornos para a pecuária leiteira.

A Tabela 4 avaliou quanto os produtores de leite estão comprometidos com a atividade, demonstrando as dificuldades enfrentadas para o desenvolvimento da produção de leite. A maior dificuldade enfrentada por eles, com $77,6 \%$ de ocorrências é o alto custo de produção, seguido por $57,9 \%$ de falta de compradores para o leite produzido. Vale ressaltar que a amostra avaliada fornece a produção para o laticínio de Douradoquara, e mesmo assim eles percebem dificuldades para escoarem a produção. Metade dos produtores alegou falta de apoio financeiro.

Conforme Schone et al (2010) é observado que a atividade leiteira apesar de ser uma atividade que gera renda mensal, o produtor enfrenta a instabilidade da produção em si e do preço de comercialização, porém a instabilidade pode ser amenizada com assistência técnica, melhoramento do plantel, das pastagens e da qualidade do leite, já a instabilidade e os baixos preços só poderão ser reduzidos com o equilíbrio na produção, pois alguns laticínios remunerarem o produtor de acordo com a produção individual, o que não é o caso do laticínio analisado, visto que este paga um preço fixo por litro.

As expectativas para os próximos dez anos, mesmo com todas as dificuldades enfrentadas, em $54 \%$ os produtores têm a intenção de 
SOUZA, F.S. e COSTA, C. Análise da qualidade de vida do pequeno produtor de leite de um laticínio em Douradoquara - MG. PUBVET, Londrina, V. 7, N. 23, Ed. 246, Art. 1623, Dezembro, 2013.

aumentar a produção, através da expansão da atividade e investimentos e $32,9 \%$ planejam permanecer como estão.

Tabela 4: Avaliação do grau de comprometimento do pequeno produtor de leite com a atividade leiteira de um lacticínio no município de Douradoquara - MG no ano de 2011.

\section{Questões}

$$
\text { No }
$$

produtores

$$
\%
$$

\section{Indique que tipo de dificuldades enfrentadas?}
a Falta de apoio financeiro
38
b Reduzido número de trabalhadores
33
c Distância dos mercados e feiras
2
$50,0 \%$
d Falta de compradores
44
$43,4 \%$
e Falta de água
1
$2,6 \%$
f Avarias nas máquinas
2
$57,9 \%$
g Elevado custo de produção
59
$1,3 \%$
$2,6 \%$
$77,6 \%$

\section{Quais as expectativas para produção de leite nos próximos 10 anos?}
a Manter a produção
b Aumentar a produção
c Diminuir a produção
d Parar de produzir

25

$32,9 \%$

41

$54,0 \%$

1

$1,3 \%$

9

$11,8 \%$

\section{Qual a participação da família na atividade?}

a Pais
b Filhos
c Irmãos
d Genros
e Netos
f Nenhum

$1 \quad 1,3 \%$

$4 \quad 5,3 \%$

3

$3,9 \%$

\section{Você está satisfeita com o que faz?}

$\begin{array}{lll}\text { a Sim } & 66 & 86,8 \% \\ \text { b Não } & 10 & 13,2 \%\end{array}$

\section{Qual a origem de sua renda?}

\begin{tabular}{lcc} 
a Produção de leite & 67 & $88,2 \%$ \\
b Trabalha para terceiros & 10 & $13,2 \%$ \\
c Exerce outra profissão & 18 & $23,7 \%$ \\
d Aposentadoria & 7 & $9,2 \%$ \\
\hline
\end{tabular}


Segundo Portella et al, (2002) apud Schöne et al (2010), a atividade leiteira apresenta particularidades em relação a mão de obra utilizada, visto que é uma atividade adequada à produção de caráter familiar, pois apresenta alta absorção de mão-de-obra e exerce importante papel na renda dos agricultores, assim muitos agricultores utilizam o grupo familiar para executar as atividades da fazenda.

Assim, esse estudo identificou como é a participação dos agregados familiares na produção do leite e em $84,2 \%$ além dos produtores entrevistados, os pais destes também participam das tarefas. Em 34,2\% os filhos colaboram. Ao serem questionados sobre a satisfação com 0 desenvolvimento da atividade leiteira, os produtores em $86,8 \%$ dos casos admitiram estarem satisfeitos com o que fazem, mesmo enfrentando dificuldades e obstáculos. Já os 13,2\% restantes declararam insatisfação com a atividade leiteira. Se comparar esse valor com o percentual de produtores que desejam abandonar a atividade, com $11,8 \%$, os índices encontram-se bem próximos. O último aspecto avaliado foi a origem da renda dos produtores e em $88,2 \%$ a renda deles é oriunda da atividade em questão. A aposentadoria ocorre como complemento em 9,2\% dos entrevistados, percentual muito baixo ao comparar-se a ocorrência de $18,4 \%$ dos produtores tem mais de 66 anos.

\section{Considerações finais}

Apesar das dificuldades enfrentadas os produtores estão em grande parte satisfeitos com o que fazem, pretendendo ainda expandir e aperfeiçoar a produção leiteira. Grande parte dos produtores em questão são donos de suas propriedades e em sua maioria esse fato ocorreu através da compra, ou seja, eles escolheram essa atividade e investiram para exercerem a produção de leite. Em relação ao tempo de desenvolvimento da atividade mais de metade deles já produzem leite há mais de 20 anos. Ao analisar o poder de compra desses produtores, fica evidente que apesar das dificuldades, eles conseguem com a renda originada do leite, possuir bens 
SOUZA, F.S. e COSTA, C. Análise da qualidade de vida do pequeno produtor de leite de um laticínio em Douradoquara - MG. PUBVET, Londrina, V. 7, N. 23, Ed. 246, Art. 1623, Dezembro, 2013.

duráveis e não duráveis. De modo geral, a atividade leiteira apresenta obstáculos e dificuldades, porém também apresenta benefícios para seus produtores, e mesmo que as vantagens não sejam exorbitantes, a renda advinda da venda do leite é capaz de suprir as necessidades de seus produtores e proporcionar a eles qualidade de vida adequada a sobrevivência, visto que quase toda a amostra declararam que estão satisfeitos com a atividade exercida e que esta satisfazem suas necessidades.

\section{Bibliografia}

BALSADI, Otavio Valentim; GOMES, Eliane Gonçalves. Evolução das Condições de Vida das Famílias dos Empregados na Agricultura Brasileira no Período 1992-2004. Revista de Economia Agrícola, São Paulo, v. 54, n. 2, p. 67-101, jul./dez. 2007.

BARROS, Ângela; DOMINGUES, Flávia; TEDRUS, Guilherme Almeida Souza; KOOP, Lais; CARLOS, Laura Emilia; FRANQUITTO, Márcia Karine; PENTEADO, Rosângela de Fátima Stankowitz; BARROS, Solange de Moraes. Apoio técnico aos pequenos produtores de leite do município de Teixeira Soares: diagnóstico. Revista Conexão UEPG, 4 ed., 2008, p. 7983.

BARROS, F L A; LIMA, J R F; FERNANDES, R A S. Análise da estrutura de mercado na cadeia produtiva do leite no período de 1998 a 2008. Revista de Economia e Agronegócio, Campina Grande, v. 8, n. 2, p. 177-198. 2010.

BORGES, Marcio Silva; DRUMOND, Maria Cristina; GUEDES, Cezar de Miranda; ALIMONDA, Héctor. O Processo de Modernização da Produção de Leite no Brasil e Argentina e Seus Impactos Sobre a Produtividade e o Trabalho Para a Pequena Produção. In: ENAPEGS, 5, 2011, Florianópolis. Anais... Florianópolis: ENAPEGS, 2011. p. 1-17. 2011.

BRITO; Brígida Rocha. Estudo Socioeconómico e Diagnóstico para Acompanhamento das Condições de Bem-Estar das Famílias da Região de Cacheu. 2006. Disponível em: <www.fao.org >. Acesso em 15 set 2011.

CARVALHO, Kátia Maria Góis de Alencar Setton; SOUZA, Mariluce Paes de; BRASIL, Caroline Estefanie do Amaral. Qualidade de Vida no Trabalho do Produtor Rural: Origem, Evolução e Perspectivas. In: Congresso Latino Americano de Sociologia Rural, 8, 2010, Porto de Galinhas. Anais... Porto de Galinhas: ALASRU, 2010. p. [s.n.].

CIDADES. Disponível em: <http://www.ibge.gov.br>. Acesso em 22 out 2011.

CORONEL, Daniel Arruda; MACHADO, João Armando Dessimon; DUTRA, Alberto da Silva. Os modelos de equilíbrio parcial como apoio a tomada de decisão do agronegócio Brasileiro: uma análise a partir dos modelos de vantagens comparativas reveladas e orientação regional. In: SOBER, 45, 2007, Londrina. Anais... Londrina: SOBER, 2007. p. 1-13. 
DIAWARA, M; GOMES, M F M; LIRIO, V S; TOSTA, M C R. Dimensionamento do agronegócio no Estado de Minas Gerais. Viçosa: UFV, 2005.

FERREIRA, Marcos Brandão Dias; LOPES, Beatriz Cordenonsi; FERREIRA, José Joaquim. Sustentabilidade do Sistema de Produção de Leite com Animais F1: Perspectivas e Pesquisa. In: MADALENA, Fernando Enrique; MATOS, Leovegildo Lopes de; HOLANDA, Evandro Vasconcelos Junior. Produção de Leite e Sociedade: Uma análise crítica da cadeia do leite no Brasil. Belo Horizonte: FEPMVZ, 2001. cap. 24, p. 383-404.

GOMES, Sebastião Teixeira. Leite era o patinho feio do agronegócio. Universidade Federal de Viçosa. Corpo Docente. Departamento de Economia Rural. Minas Gerais: 2007. Disponível em: <http://www.ufv.br>. Acesso em: 06 out. 2011.

HERCULANO, Selene C. A Qualidade de Vida e Seus Indicadores. In: HERCULANO, Selene C. (org.). Qualidade de Vida e Riscos Ambientais. Niterói: Eduff, 2000. p. [s.n.]

MESQUITA, B A. Demanda por alimentos e a consequência na Amazônia Brasileira: Sucesso do agronegócio e tragédia do desmatamento. São Luís: UFMA, 2007.

NEVES, M F. Planejamento e gestão estratégica de cadeias produtivas visando competitividade: aplicações nos agronegócios. Ribeirão Preto: USP, 2007.

PACHECO, Mariane de Souza. Leite Cru Refrigerado do Agreste Pernambucano: Caracterização da Qualidade e do Sistema de Produção. 2011. 87 f. Dissertação (PósGraduação em Ciência e Tecnologia de Alimentos) - Universidade Federal Rural de Pernambuco, Departamento De Ciências Domésticas, Recife. 2011.

PERES, J R R. Transgêncios: os benefícios para um agronegócio sustentável. Brasília: Empresa Brasileira de Pesquisa Agropecuária, 2001.

SANTOS, G. T.; VILELA, D. Produção Leiteira: Analisando O Passado, Entendendo O Presente E Planejando O Futuro. In: SBZ, 37, 2000, Viçosa. Anais... Viçosa: SBZ, 2000. p. 231-266.

SANTOS, Priscila Alonso dos. Avaliação do Leite Cru Refrigerado Produzido na Região Sudoeste do Estado de Goiás Estocado Por Diferentes Períodos. 2008. 50 f. Tese (Doutorado em Ciência Animal) - Escola De Veterinária, Universidade Federal de Goiás, Goiânia. 2008.

SCHÖNE, Joana; SILVA, Nardel Luiz Soares da; FEIDEN, Armin; ZONIN, Wilson João; SILVA, Pedro Celso Soares da. Estudo de caso da produção leiteira da agricultura familiar de Catanduvas-PR. Revista Cultivando o Saber, Cascavel, v.3, n.3, p.116-124, 2010.

SOUZA, Raquel Pereira; WAQUIL, Paulo Dabdab. A Viabilidade da Agricultura Familiar Produtora de Leite: O Caso do Sistema COORLAC (RS). In: XLVI congresso da Sociedade Brasileira de Economia, Administração e Sociologia Rural, Rio Branco, 2008.

ZOCCAL, Rosangela; SOUZA, Antonio Domingues de; GOMES Aloísio Teixeira; LEITE, José Luiz Bellini. Produção de Leite na Agricultura Familiar. In: SOBER, 12, 2004, Cuiabá.

Anais... Cuiabá: SOBER, 2004. p. 1-12. 